\title{
High Efficient Synthesis of Enzymatic 2-Ethylhexyl Ferulate at Solvent-Free and Reduced Pressure Evaporation System
}

\author{
Kuo-Chuan Huang1, Ying Li², Yawo-Kuo Twu' ${ }^{1}$, Chwen-Jen Shieh ${ }^{2 *}$ \\ ${ }^{1}$ Department of Biolndustry Technology, DAYEH University, Changhua, Taiwan \\ ${ }^{2}$ Biotechnology Center, National Chung Hsing University, Taichung, Taiwan \\ Email: ${ }^{*}$ cjshieh@nchu.edu.tw
}

Received April 2015

\begin{abstract}
The use of immobilized lipase from Candida antarctica (Novozym ${ }^{\circledR} 435$ ) to catalyze ferulic acid of esterification was investigated in this study. The synthesis product was analyzed using HPLC. The results revealed that the major product was 2 -ethylhexyl ferulate. Response surface methodology and 3-level-3-factor central composite rotatable design were adopted to evaluate the effects of synthesis variables, including reaction temperature $\left(60^{\circ} \mathrm{C}-80^{\circ} \mathrm{C}\right)$, enzyme amount (500 - $\left.1500 \mathrm{PLU}\right)$ and reaction time ( 8 - $24 \mathrm{~h}$ ) on the percentage molar conversion of 2-ethylhexyl ferulate. The results showed that reaction temperature and reaction time were the most important parameters on percentage molar conversion. Based on ridge max analysis, the optimum conditions for synthesis were: reaction time $23 \mathrm{~h}$, reaction temperature $71^{\circ} \mathrm{C}$ and enzyme amount $1422 \mathrm{PLU}$. The molar conversion of actual experimental values was $98 \%$ under optimal conditions.
\end{abstract}

\section{Keywords}

Ferulic Acid, Green Chemistry, Novozym ${ }^{\circledR}$ 435, Rotary Evaporator, Esterification

\section{Introduction}

Ferulic acid (4-hydroxy-3-methoxy cinnamic acid, FA) belongs to the family of phenolic acids and is very abundant in grains, fruits and vegetables. It has a capacity of antioxidation [1], excellent UV-absorbing, antitumor activity [2] [3], potential health benefits against cardiovascular problems, inflammatory diseases and cancer [4], which find a variety of applications in the pharmaceutical, cosmetic and food industries. The solubility of ferulic acid in either a hydrophobic or hydrophilic solvent is low and thus limits its application. Therefore, to apply natural phenolic acids in lipophilic formulation and processing, lipophilization is needed where enzymatic esterification with alcohols has proved itself to be a promising approach [5]-[8]. In recent years, a number of studies reported the enzymatic synthesis of hydrophobic derivatives of ferulic acid to increase its oil-solubility [9]-[11].

Chemical synthesis of these derivatives is difficult, as FA is susceptible to oxidation under certain $\mathrm{pH}$ condi-

\footnotetext{
"Corresponding author.
} 
tions [12]-[14]. Thus, enzymatic biosynthesis of FA lipids has been used as an attractive alternative to the conventional chemical processes [15]. Environment-friendly preparation of hydrophobic derivatives of FA is therefore a challenge for research. Enzymatic direct esterifications of FA with aliphatic alcohols have been reported [16]. Hydrophilic feruloylated derivatives can be produced using the esterification of FA with alcohols. The strategy of esterification of hydrophilic FA with lipophilic molecules, such as aliphatic alcohols, can be employed to alter its solubility in a hydrophobic medium. The esterification of FA with monosaccharides as well as n-octyl glycoside to produced hydrophilic feruloylated derivatives. The water-soluble derivative of glyceryl ferulate was biosynthesized by esterification of FA with glycerol using pectinase [17]. Solvent-free enzymatic transesterification of EF with triolein (TO) with a higher EF conversion 77\% [18]. However, the reaction rate for the condensation of FA with an alcoholic substrate is low because FA has conjugation with a carboxyl group and a bulky noncarboxylic region [19].

In this study, lipase-catalyzed transesterification of FA to biosynthesis 2-ethylhexyl ferulate was optimized. In order to optimise the biosynthesis conditions, including concentration of solvent, reaction temperature, enzyme load, reaction time, duty cycle, and solvent-to-material ratio, response surface methodology (RSM) has been used. By establishing a mathematical model, RSM evaluates multiple parameters and their interactions using quantitative data, effectively optimising complex extraction procedures in a statistical way, thus reducing the number of experimental trials required.

\section{Experimental Procedure}

\subsection{Materials and Methods}

Immobilized lipase Novozyms ${ }^{\circledR} 435$ (10,000 U/g; propyl laurate units (PLU)) from Candida antarctica B (EC3.1.1.3) supported on a macroporous acrylic resin was purchased from NovoNor disk Bioindustrials Inc. (Copenhagen, Denmark). Ferulic acid (FA), 2-ethyl hexanol (2-EH), 2-methyl-2-butanol (2M2B), methanol and acetic acid were purchased from the Sigma Chemical Co. (St. Louis, MO). A molecular sieve $4 \AA$ was purchased from Davison Chemical (Baltimore, MD, USA). All other reagents and chemicals, unless otherwise noted, were of analytical grade.

\subsection{Enzymatic Synthesis of 2-Ethylhexyl Ferulate}

All materials were dehydrated by a molecular sieve $4 \AA$ for 24 h before use. Ferulic acid $(0.05 \mathrm{M})$ and Novozym ${ }^{\circledR} 435$ were well mixed with $1 \mathrm{~mL}$ 2-ethyl hexanol (2-EH) (substrate molar ratio 1:123) at $80 \mathrm{rpm}$ and 560 torr by the rotary evaporator (EYELA N-1100, Tokyo Rikakikai Co., Ltd.). The volume is 6 fingernails emissions glass flask. The diameter of the capillary is $2 \mathrm{~cm}$. The transesterification of ferulic acid catalyzed by Novozym $^{\circledR} 435$ is represented in Figure 1.

Liquid samples were withdrawn from the reaction mixture and analyzed by high-performance liquid chromatography (HPLC). Samples were centrifuged and diluted with hexanol/2-methyl-2-butanol (1:150). Analysis was done by $30 \mathrm{~L}$ of the reaction mixture into a HPLC (Hitachi L-7400; Tokyo, Japan) and a Thermo C18 column (250 cm $4.6 \mathrm{~mm}$, Agilent, USA) was used. Separations were carried out using a gradient elution by employing $0.1 \%$ acetic acid and methanol. The reaction mixture separation was achieved by an elution system consisting of $0.1 \%$ acetic acid and methanol for the last 5.5 minutes. The flow rate was $1.0 \mathrm{~mL} / \mathrm{min}$ and sampling was detected under UV light at $325 \mathrm{~nm}$. The molar conversion were calculated from the peak areas of the sample.

\subsection{Experimental Design}

A 3-level-3-factor Box-Behnken was employed in this study, requiring 15 experiments. To avoid bias, the 15

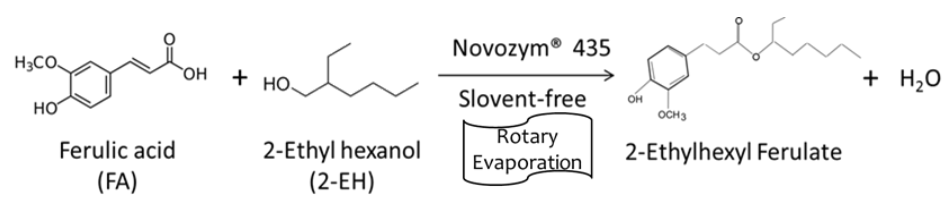

Figure 1. Scheme of enzymatic synthesis of 2-ethylhexyl ferulate catalyzed by Novozym ${ }^{\circledR} 435$. 
runs were performed in a totally random order. The variables and their levels selected for the study of 2-ethylhexyl ferulate biosynthesis were: reaction temperature $\left(60^{\circ} \mathrm{C}-80^{\circ} \mathrm{C}\right)$, enzyme amount (500 - $\left.1500 \mathrm{PLU}\right)$ and reaction time ( 8 - 24 h). Table 1 shows the independent factors (xi), levels and experimental design in terms of coded and uncoded.

\subsection{Statistical Analysis}

The experimental data were then analyzed by the response surface regression (RSREG) procedure with design expert software to fit the following second-order polynomial Equation (1):

$$
Y=\beta_{0}+\sum_{i=1}^{3} \beta_{i} x_{i}+\sum_{i=1}^{3} \beta_{i i} x_{i}^{2}+\sum_{i=1}^{2} \sum_{j=i+1}^{3} \beta_{i j} x_{i} x_{j}
$$

where $Y$ is the molar conversion of 2-ethylhexyl ferulate; $\beta_{0}$ is a constant, $\beta_{i}, \beta_{i i}$ and $\beta_{i j}$ are constant coefficients; and $x_{i}$ and $x_{j}$ are uncoded independent variables. The suffixes $I$ and $j$ are seen in the above equation with the three independent variables denoting: $x_{1}$ for reaction time, $x_{2}$ for enzyme amount and $x_{3}$ for reaction temperature. The option of a ridge max option in the design expert software was employed to compute the estimated ridge of maximum response when increasing the radius from the center of the original design.

\section{Results and Discussion}

\subsection{Primary Experiment}

The lipase-catalyzed synthesis of 2-ethylhexyl ferulate from ferulic acid and 2-ethyl hexanol was carried out with oil bath by rotary evaporator. The reaction conditions were set at reaction temperature $70^{\circ} \mathrm{C}$, substrate molar ratio1 : 123 (ferulic acid: 2-ethyl hexanol), enzyme amount 1970 PLU, reaction time 24 h, 80 rpm, and 560 torr. The HPLC chromatogram at $325 \mathrm{~nm}$ for the reaction mixture is shown in Figure 2. Ferulic acid (2.85 min) has a shorter retention time in the C18 column. However, 2-ethylhexyl ferulate (7.37 $\mathrm{min})$ has a longer retention time, because transesterification increases its hydrophobicity.

Table 1. Box-Behnken rotatable design and experimental data for 3-level-3-factor response surface analysis.

\begin{tabular}{|c|c|c|c|c|}
\hline \multirow[b]{2}{*}{ Run } & \multicolumn{3}{|c|}{ Independent variable } & \multirow[b]{2}{*}{ Molar conversion( $\%$ ) } \\
\hline & $\underset{\text { Time(h) }}{\mathbf{X l}}$ & $\underset{\text { enzyme(PLU) }}{\mathrm{X} 2}$ & $\begin{array}{c}\mathrm{X} 3 \\
\text { Temperature(C) }\end{array}$ & \\
\hline 1 & 8 & 1000 & 60 & $42.7 \pm 3.3$ \\
\hline 2 & 24 & 1000 & 60 & $64.2 \pm 2.1$ \\
\hline 3 & 8 & 1000 & 80 & $86.3 \pm 2.8$ \\
\hline 4 & 24 & 1000 & 80 & $98.7 \pm 1.9$ \\
\hline 5 & 8 & 500 & 70 & $68.7 \pm 4.1$ \\
\hline 6 & 24 & 500 & 70 & $82.3 \pm 3.2$ \\
\hline 7 & 8 & 1500 & 70 & $80.4 \pm 2.1$ \\
\hline 8 & 24 & 1500 & 70 & $98.8 \pm 1.6$ \\
\hline 9 & 16 & 500 & 60 & $39.8 \pm 2.7$ \\
\hline 10 & 16 & 500 & 80 & $85.7 \pm 3.4$ \\
\hline 11 & 16 & 1500 & 60 & $44.8 \pm 4.2$ \\
\hline 12 & 16 & 1500 & 80 & $98.9 \pm 2.5$ \\
\hline 13 & 16 & 1000 & 70 & $92.4 \pm 3.1$ \\
\hline 14 & 16 & 1000 & 70 & $92.0 \pm 2.8$ \\
\hline 15 & 16 & 1000 & 70 & $91.7 \pm 2.3$ \\
\hline
\end{tabular}




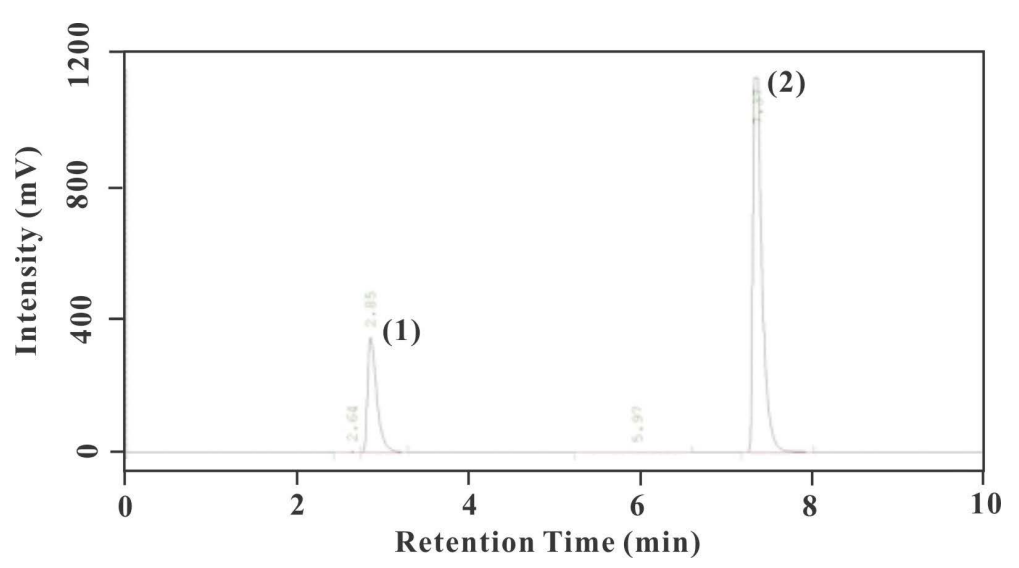

Figure 2. HPLC analysis of the reaction mixture for (1) ferulic acid, (2) 2ethylhexyl ferulate.

The reaction time course for the transesterification of ferulic acid by Novozym ${ }^{\circledR} 435$ was shown as Figure 3 (A). The percent molar conversion of 2-ethylhexyl ferulate increased to $81.66 \%$ at $8 \mathrm{~h}$. The selection of reaction time range needs to be extremely precise in studies of CCRD, otherwise the optimal condition of synthesis cannot be found inside the experimental region through the analyses of statistics and contour plots. The reaction temperature course for the biosynthesis of 2-ethylhexyl ferulate was shown as Figure 3(b). The percent molar conversion of 2-ethylhexyl ferulate increased to $83.83 \%$ at $80^{\circ} \mathrm{C}, 8 \mathrm{~h}$. The results indicated increase of molar conversion by high temperature. It is well known that the reaction temperature is a crucial parameter in biocatalysis. From report, enzymatic transesterification of ethyl ferulate (EF) and monostearin for feruloylated lipids production was investigated. The optimum condition of reaction temperature was $74^{\circ} \mathrm{C}$. A novel enzymatic route of feruloylated structured lipids synthesis by the transesterification of EF with castor oil, in solvent-free system, was investigated. High EF conversion was obtained under the reaction temperature $90^{\circ} \mathrm{C}$ [20]. The temperature also has a large effect on the thermodynamic equilibrium of a reversible reaction. The enzyme amount course for the bioctatlysis of 2-ethylhexyl ferulate was shown as Figure 3(c). The percent molar conversion of 2ethylhexyl ferulate increased to $90.16 \%$ at 2000 PLU. From preliminary experimental data, the variables and their levels selected in this study were: reaction time $(8-24 \mathrm{~h})$, temperature $\left(60^{\circ} \mathrm{C}-80^{\circ} \mathrm{C}\right)$, and enzyme amount (500 - 1500 PLU), as shown in Table 1.

\subsection{Model Fitting}

In order to systemically understand the relationships between reaction temperature, enzyme amount and time for the synthesis of 2-ethylhexyl ferulate, a 3-level-3-factor Box-Behnken design was applied and a total of 15 treatments (experiments) were carried out. The main objective of this work was to develop and evaluate a statistical approach to better understand the relationship among the variables and the response (percent molar conversion of 2-ethylhexyl ferulate). On the basis of this concept, a large-scale process can be optimized with lower costs in terms of time and labor requirements. In comparison with the one-factor-at-a-time design, response surface methodology (RSM), as employed in this study, is more efficient in reducing the experimental runs and time for optimal 2-ethylhexyl ferulate production.

The RSM procedure for Box-Behnken was employed to fit the second-order polynomial equation to the experimental data (Table 1). Among the various treatments, the highest mole conversion $(98.9 \% \pm 2.5 \%)$ was treatment 12 (reaction temperature $80^{\circ} \mathrm{C}$, enzyme amount $1500 \mathrm{PLU}$ and reaction time $16 \mathrm{~h}$ ), and the lowest mole conversion $\left(42.7 \% \pm 3.3 \%\right.$ ) was treatment 1 (reaction temperature $60^{\circ} \mathrm{C}$, enzyme amount $1000 \mathrm{PLU}$ and reaction time $8 \mathrm{~h}$ ). The second-order polynomial Equation (2) obtained was as follows:

$$
\begin{aligned}
Y= & -968.26667+3.60052 X_{1}+26.28208 X_{2}+0.039783 X_{3}-0.027812 X_{1} X_{2} \\
& +0.0003 X_{1} X_{3}+0.0004 X_{2} X_{3}-0.028971 X_{1}^{2}-0.17154 X_{2}^{2}-0.0000305167 X_{3}^{2}
\end{aligned}
$$

The analysis of variance (ANOVA), represented in Table 2, indicated that this second-order polynomial model was highly significant and adequate to represent the actual relationship between the response (percentage 


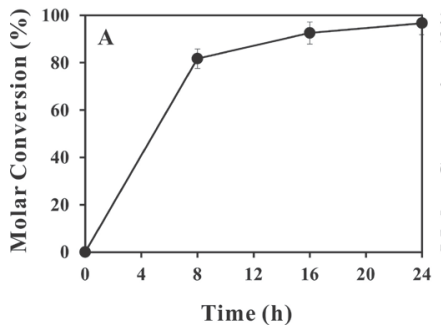

(a)

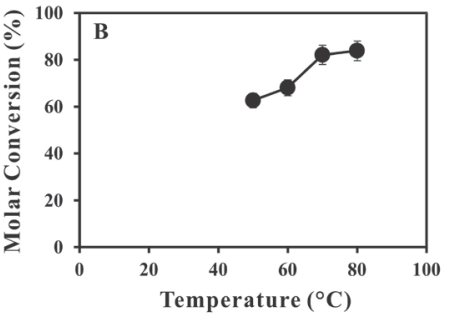

(b)

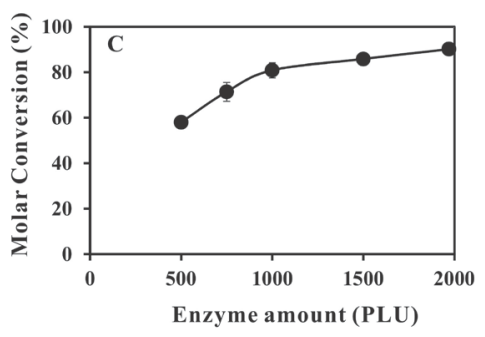

(c)

Figure 3. The reaction was carried out at (a) reaction time $0-24 \mathrm{~h}$; (b) reaction temperature $50^{\circ} \mathrm{C}-80^{\circ} \mathrm{C}$ and (c) enzyme amount 500 - 2000 P LU, substrate molar ratio of 1:123 in $80 \mathrm{rpm}$ and 560 torr by the rotary evaporator.

Table 2. ANOVA for synthetic variables pertaining to the response of molar conversion.

\begin{tabular}{cccccc}
\hline Source & Sum of squares & df & Mean square & F value & $\begin{array}{c}\text { p-value } \\
\text { prob }>\text { F }\end{array}$ \\
\hline Model & 22.5 & 9 & 2.5 & 37.08 & 0.0005 \\
A-time & 1.87 & 1 & 1.87 & 27.68 & 0.0033 \\
B-temperature & 14.72 & 1 & 14.72 & 218.3 & $<0.0001$ \\
C-enzyme & 0.85 & 1 & 0.85 & 12.61 & 0.0614 \\
AB & 0.17 & 1 & 0.17 & 2.48 & 0.1762 \\
AC & 0.0090 & 1 & 0.0090 & 0.13 & 0.7297 \\
BC & 0.021 & 1 & 0.021 & 0.32 & 0.5973 \\
A & 0.015 & 1 & 0.015 & 0.23 & 0.6545 \\
B & 4.33 & 1 & 4.33 & 64.15 & 0.0005 \\
C & 0.79 & 1 & 0.79 & 11.71 & 0.0188 \\
Residual & 16.18 & 5 & 3.24 & & 0.09 \\
Lack of Fit & 15.2 & 3 & 5.07 & 10.27 & \\
Pure Error & 0.99 & 2 & 0.49 & &
\end{tabular}

molar conversion) and the significant variables with a very small p value is $0.0005(<0.001)$ and a satisfactory coefficient of determination $\left(\mathrm{R}^{2}=0.9852\right)$. The ANOVA results of responses reveal an insignificant "lack of fit" for $\mathrm{p}>0.05$. Therefore, these models were adequate for prediction within the range of variables employed. Furthermore, the ANOVA results indicate that the linear terms had significant $(\mathrm{p}<0.05)$ influence on molar conversion. The quadratic and cross product terms had less influence $(\mathrm{p}>0.05)$.

\subsection{Mutual Effect of Parameters}

The effect of varying reaction temperature and enzyme amount on transesterification efficiency at a constant reaction time of $16 \mathrm{~h}$ is shown in Figure 4(a). With the highest reaction temperature $\left(80^{\circ} \mathrm{C}\right)$ and enzyme amount (1500 PLU), 2-ethylhexyl ferulate molar conversion of $98.9 \% \pm 2.5 \%$ was obtained, when the enzyme amount was decreased to $500 \mathrm{PLU}$ and the reaction temperature was decreased to $60^{\circ} \mathrm{C}$, only $39.8 \% \pm 2.7 \%$ molar conversion remained. Figure 4(b) shows the effects of reaction time and reaction temperature on 2-ethylhexyl ferulate biosynthesis at a constant enzyme amount (1000 PLU). At the lowest reaction time (8 h) and reaction temperature $\left(60^{\circ} \mathrm{C}\right)$, the molar conversion was $42.7 \% \pm 3.3 \%$. The molar conversion increased when the reaction temperature and reaction time increased. These results revealed that reaction temperature and reaction time are most important parameters on the molar conversion of 2-ethylhexyl ferulate.

\subsection{Optimal Optimum Synthesis Conditions}

The optimum biosynthesis of 2-ethylhexyl ferulate was determined by the ridge max analysis, which showed that the maximum molar conversion was $98.9 \% \pm 2.5 \%$ at $16 \mathrm{~h}$, temperature $80^{\circ} \mathrm{C}$ and enzyme amount 1,500 PLU. The represents the correlation between the experimental values and the predicted values of RSM model for 
average cutting speed. A verification experiment performed at the suggested optimum conditions obtained a molar conversion of $99.5 \% \pm 1.5 \%$, which was close to the predicted molar conversion; thus, the predicted model was successfully developed. In this study, the lipase-catalyzed biosynthesis of 2-ethylhexyl ferulate was carried out with easy method. The enzyme esterification of phenolic compounds is usually reacted with an excess amount of acyl acceptor or donor due to the steric hindrance caused by benzoic structure. In this study, increased of reaction temperature would result in a higher molar conversion of product; however, extremely high temperature might inhibit the enzyme.

To examine the enzyme reusability, the ability of immobilized lipase for 2-ethylhexyl ferulate synthesis was investigated under optimum conditions in Figure 5. The immobilized lipase was recovered from the reaction

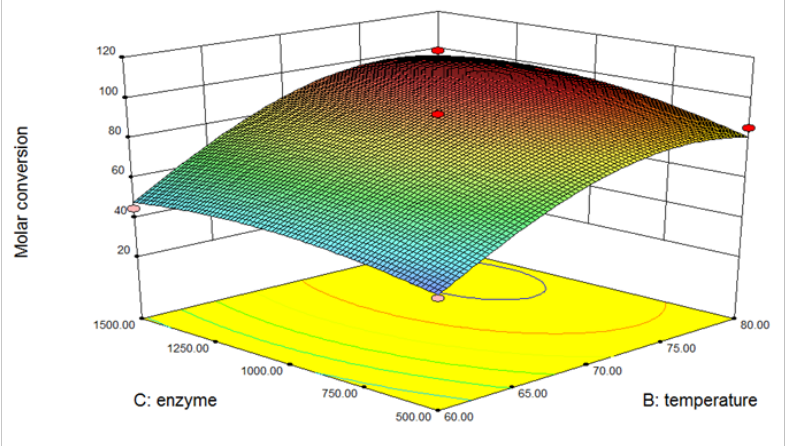

(a)

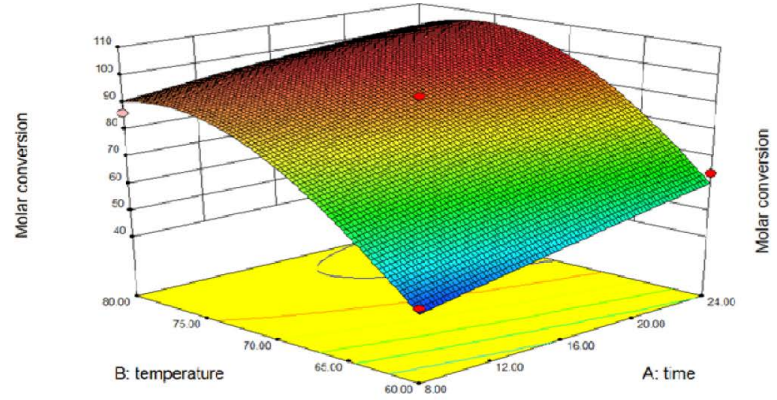

(b)

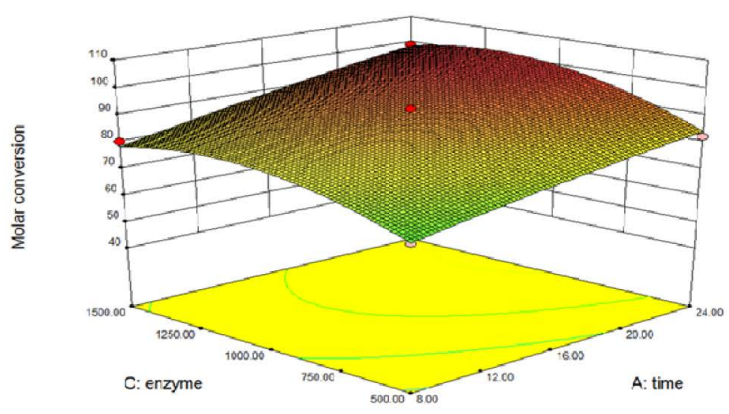

(c)

Figure 4. Response surface plot showing the relationships between 2-ethylhexyl ferulate molar conversion and reaction parameters: (a) reaction temperature and enzyme amount; (b) reaction temperature and reaction time and (c) reaction time and enzyme amount.

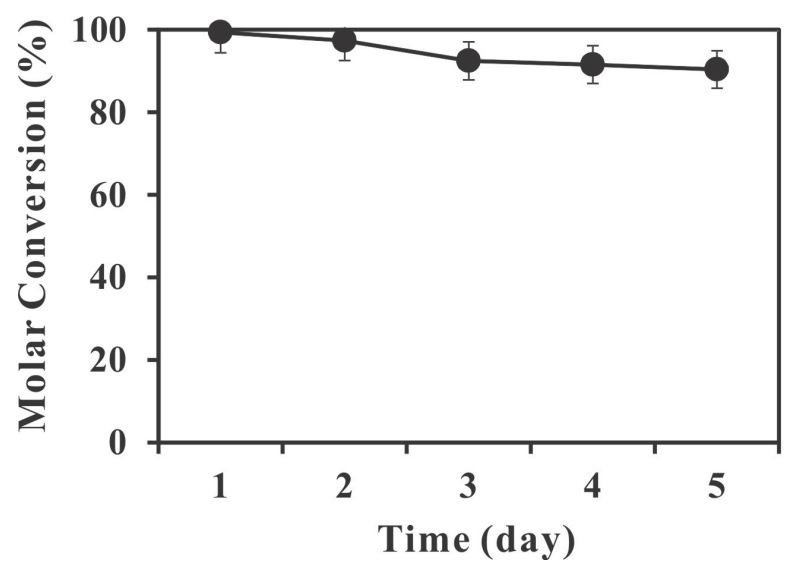

Figure 5. Reusability of Novozym ${ }^{\circledR} 435$ to synthesis 2-ethylhexyl ferulate under an operating condition of $71^{\circ} \mathrm{C}, 1422 \mathrm{PLU}$, $23 \mathrm{~h}$, substrate molar ratio of 1:123 in $80 \mathrm{rpm}$ and 560 torr by the rotary evaporator. 
medium after reaction and directly reused in the next batch. After the batch of immobilized lipase was reused 5 times, the molar conversion of 2-ethylhexyl ferulate still remained at about $90.4 \%$. This result showed that the immobilized lipase remained stable through a long-term 2-ethylhexyl l exposure. Thus, the result demonstrated that the lipase could be effectively applied for 2-ethylhexyl ferulate synthesis and that the stability was high enough to permit reuse. Novozym ${ }^{\circledR} 435$ showed the best catalysis performance, which made the work more suitable for feruloyl structured lipids preparation, due to the oxidizability and heat sensitivity of 2-ethylhexyl ferulate.

\section{Conclusion}

The immobilized C. antarctica lipase is able to synthesis of 2-ethylhexyl ferulate. A 3-level-3-factor RSM and Box-Behnken were employed for the experimental design and data analysis. A model for the 2-ethylhexyl ferulate synthesis was built and the optimal synthesis condition was in a reaction time of $23 \mathrm{~h}$, reaction temperature of $71^{\circ} \mathrm{C}$ and enzyme amount $1422 \mathrm{PLU}$. Biosynthesis of 2-ethylhexyl ferulate under this optimal condition was actually performed and $99.5 \% \pm 1.5 \%$ conversion was obtained. The results indicate that the temperature affected the enzymatic synthesis significantly. In this experiment, green chemistry, based in solvent-free system, breaking the previous ferulic acid lipid synthesis time, the time will be shortened to one day, the conversion rate as high as $99.5 \%$.

\section{References}

[1] Liu, J., Wen, X.Y., Lu, J.F., Kan, J. and Jin, C.H. (2014) Free Radical Mediated Grafting of Chitosan with Caffeic and Ferulic Acids: Structures and Antioxidant Activity. International Journal of Biological Macromolecules, 65, 97-106. http://dx.doi.org/10.1016/j.ijbiomac.2014.01.021

[2] Choo, W.S. and Birch, E.J. (2009) Radical Scavenging Activity of Lipophilized Products from Lipase-Catalyzed Transesterification of Triolein with Cinnamic and Ferulic Acids. Lipids, 44, 145-152. http://dx.doi.org/10.1007/s11745-008-3242-X

[3] Itagaki, S., Kurokawa, T., Nakata, C., Saito, Y., Oikawa, S. and Kobayashi, M. (2009) In Vitro and in Vivo Antioxidant Properties of Ferulic Acid: A Comparative Study with Other Natural Oxidation Inhibitors. Food Chemistry, 114, 466471. http://dx.doi.org/10.1016/j.foodchem.2008.09.073

[4] Mancuso, C. and Santangelo, R. (2014) Ferulic Acid: Pharmacological and Toxicological Aspects. Food and Chemical Toxicology, 65, 185-195. http://dx.doi.org/10.1016/j.fct.2013.12.024

[5] Guyot, B., Bosquette, B., Pina, M. and Graille, J. (1997) Esterification of Phenolic Acids from Green Coffee with an Immobilized Lipase from Candida Antarctica in Solvent-Free Medium. Biotechnology Letters, 19, 529-532. http://dx.doi.org/10.1023/A:1018381102466

[6] Stamatis, H., Sereti, V. and Kolisis, F.N. (1999) Studies on the Enzymatic Synthesis of Lipophilic Derivatives of Natural Antioxidants. Journal of the American Oil Chemists' Society, 76, 1505-1510. http://dx.doi.org/10.1007/s11746-999-0193-1

[7] Vosmann, K., Weitkamp, P. and Weber, N. (2006) Solvent-Free Lipasecatalyzed Preparation of Long-Chain Alkyl Phenylpropanoates and Phenylpropyl Alkanoates. Journal of Agricultural and Food Chemistry, 54, 2969-2976. http://dx.doi.org/10.1021/jf060052t

[8] Stamatis, H., Sereti, V. and Kolisis, F.N. (2001) Enzymatic Synthesis of Hydrophilic and Hydrophobic Derivatives of Natural Phenolic Acids in Organic Media. Journal of Molecular Catalysis B: Enzymatic, 11, 323-328. http://dx.doi.org/10.1016/S1381-1177(00)00016-3

[9] Chigorimbo-Murefu, N.T.L., Riva, S. and Burton, S.G. (2009) Lipasecatalysed Synthesis of Esters of Ferulic Acid with Natural Compounds and Evaluation of Their Antioxidant Properties. Journal of Molecular Catalysis B: Enzymatic, 56, 277-282. http://dx.doi.org/10.1016/j.molcatb.2008.05.017

[10] Laszlo, J.A. and Compton, D. L. (2006) Enzymatic Glycerolysis and Transesterification of Vegetable Oil for Enhanced Production of Feruloylated Glycerols. Journal of the American Oil Chemists' Society, 83, 765-770.

http://handle.nal.usda.gov/10113/13929 http://dx.doi.org/10.1007/s11746-006-5012-3

[11] Sun, S., Shan, L., Jin, Q., Liu, Y. and Wang, X. (2007) Solvent-Free Synthesis of Glyceryl Ferulate Using a Commercial Microbial Lipase. Biotechnology Letters, 29, 945-949. http://dx.doi.org/10.1007/s10529-007-9338-1

[12] Yang, X.Z., Diao, X.J., Yang, W.H., Li, F., He, G.W., Gon, G.Q. and Xu, Y.G. (2013) Design, Synthesis and Antithrombotic Evaluation of Novel Dabigatran Prodrugs Containing Methyl Ferulate. Bioorganic \& Medicinal Chemistry 
Letters, 23, 2089-2092. http://dx.doi.org/10.1016/j.bmcl.2013.01.126

[13] Giuliani, S., Piana, C., Setti, L., Hochkoeppler, A., Pifferi, P.G., Williamson, G. and Faulds, C.B. (2001) Synthesis of Pentylferulate by a Feruloyl Esterase from Aspergillus Niger Using Water-In-Oil Microemulsions. Biotechnology Letters, 23, 325-330. http://dx.doi.org/10.1023/A:1005629127480

[14] Kikuzaki, H., Hisamoto, M., Hirose, K., Akiyama, K. and Taniguchi, H. (2002) Antioxidant Properties of Ferulic Acid and Its Related Compounds. Journal of Agricultural and Food Chemistry, 50, 2161-2168. http://dx.doi.org/10.1021/jf011348w

[15] Sun, S.D., Song, F.F., Bi, Y.L., Yang, G.L. and Liu, W. (2012) Solvent-Free Enzymatic Transesterification of Ethyl Ferulate and Monostearin: Optimized by Response Surface Methodology. Journal of Biotechnology, 164, 340-345. http://dx.doi.org/10.1016/j.jbiotec.2013.01.013

[16] Yoshida, Y., Kimura, Y., Kadota, M., Tsuno, T. and Adachi, S. (2006) Continuous Synthesis of Alkyl Ferulate by Immobilized Candida Antarctica Lipase at High Temperature. Biotechnology Letters, 28, 1471-1474. http://dx.doi.org/10.1007/s10529-006-9113-8

[17] Matsuo, T., Kobayashi, T., Kimura, Y., Tsuchiyama, M., Tsuchiyama, M., Oh, T., Sakamoto, T. and Adachi, S. (2008) Synthesis of Glyceryl Ferulate by Immobilized Ferulic Acid Esterase. Biotechnology Letters, 30, 2151-2156. http://dx.doi.org/10.1007/s10529-008-9814-2

[18] Compton, D.L., Laszlo, J.A. and Berhow, M.A. (2000) Lipase-Catalyzed Synthesis of Ferulate Esters. Journal of the American Oil Chemists' Society, 77, 513-519. http://dx.doi.org/10.1007/s11746-000-0082-9

[19] Kobayashi, T., Adachi, S. and Matsuno, R. (2003) Lipase-Catalyzed Condensation of p-Methoxyphenethyl Alcohol and Carboxylic Acids with Different Steric and Electrical Properties in Acetonitrile. Biotechnology Letters, 25, 3-7. http://dx.doi.org/10.1023/A:1021799825272

[20] Sun, S.D., Zhu, S. and Bi, Y.L. (2014) Solvent-Free Enzymatic Synthesis of Feruloylated Structured Lipids by the Transesterification of Ethyl Ferulate with Castor Oil. Food Chemistry, 158, 292-295. http://dx.doi.org/10.1016/j.foodchem.2014.02.146 